\title{
BMJ Open Observational study investigating the prevalence of asymptomatic stage B heart failure in patients with type 2 diabetes who are not known to have coronary artery disease
}

Mon Myat Oo (D) , ${ }^{1}$ Isaiah Tan Chung Zhen, ${ }^{2}$ Kee Seong Ng, ${ }^{3}$ Kok Leng Tan, ${ }^{1}$ Alexander T B Tan, ${ }^{1}$ Shireene Ratna Vethakkan, ${ }^{4}$ R Jeyakantha A/L Ratnasingam, ${ }^{1}$ Kok Han Chee ${ }^{1}$

To cite: 0 o MM, Tan Chung Zhen I, Ng KS, et al. Observational study investigating the prevalence of asymptomatic stage $B$ heart failure in patients with type 2 diabetes who are not known to have coronary artery disease. BMJ Open 2021;11:e039869. doi:10.1136/ bmjopen-2020-039869

- Prepublication history for this paper is available online. To view these files, please visit the journal online (http://dx.doi. org/10.1136/bmjopen-2020039869).

Received 29 April 2020 Revised 10 December 2020 Accepted 17 December 2020

Check for updates

(c) Author(s) (or their employer(s)) 2021. Re-use permitted under CC BY-NC. No commercial re-use. See rights and permissions. Published by BMJ.

For numbered affiliations see end of article.

Correspondence to

Mon Myat 00;

monmyat85@gmail.com

\section{ABSTRACT}

Objective To identify the prevalence of stage B heart failure (SBHF) in patients with type 2 diabetes mellitus (T2DM) with no history of cardiovascular disease (CVD). Design Observational study.

Setting A single-centre study in which eligible patients were recruited from T2DM clinic. Following consent, patients completed a questionnaire and underwent physical examinations. Patients had blood drawn for laboratory investigations and had a transthoracic echocardiography.

Participants A total of 305 patients who were not known to have CVD were recruited. Patients with deranged liver function tests and end stage renal failure were excluded.

Main outcome measures Echocardiographic parameters such as left ventricular ejection fraction, left ventricular mass index (LVMI), left ventricular hypertrophy, left atrial enlargement and diastolic function were examined. Results A total of 305 patients predominantly females (65\%), with mean body mass index of $27.5 \mathrm{~kg} / \mathrm{m}^{2}$ participated in this study. None of them had either a history or signs and symptoms of CVD. Seventy-seven percent of patients had a history of hypertension and $83 \%$ of this study population had T2DM for more than 10 years. Mean HbA1c of $8.3 \%$ was recorded. Almost all patients were taking metformin. Approximately, $40 \%$ of patients were on newer anti-T2DM agents such as sodium-glucose cotransporter-2 and dipeptidyl peptidase 4 inhibitors. Fifty-seven percent $(n=174)$ of the study population had SBHF at the time of study: diastolic dysfunction, increased LVMI and increased left atrial volume index (LAVI) were noted in 51 patients (17\%), 128 patients (42\%) and 98 patients (32\%), respectively. Thirty-seven patients (12\%) had both increase LVMI and LAVI. Conclusion Our study has revealed a high prevalence of SBHF in T2DM patients without overt cardiac disease in Malaysia that has one of the highest prevalence of TDM in the world.

\section{INTRODUCTION}

A dramatic increase in prevalence of type 2 diabetes mellitus (T2DM) from 4.7\% in 1980
Strengths and limitations of this study

- First study reporting the prevalence of stage B heart failure in type 2 diabetes mellitus (T2DM) patients with no history of coronary artery disease from Malaysia that has one of the highest prevalence of T2DM in the world is of interest.

- Comprehensive 2-dimensional echocardiography was performed to identify structural and functional abnormalities of study population.

- A limitation is the absence of assessment of global longitudinal strain in our study.

to $8.5 \%$ in 2014 was reported globally. ${ }^{1}$ In 2016, an estimated 1.6 million deaths were directly caused by T2DM. ${ }^{1}$ In Malaysia, the prevalence of T2DM is one of the highest in the world with 3.6 million individuals affected ( $16.9 \%$ of the adult population) by it. Many of these patients with T2DM are expected to succumb to cardiovascular disease-related health problems. Among them, heart failure is of most concern as it is progressive in nature with unfavourable outcome. ${ }^{2-4}$ Incidence of heart failure in T2DM is two to fivefolds higher irrespective of concomitant risk factors such as hypertension, coronary artery disease and any other cardiac disease. ${ }^{5}$ T2DM increases the relative risk of various vascular events by twofold in men and threefold in women. In the case of heart failure, the relative risk is eightfold higher in women. ${ }^{6}$ Several pathophysiological mechanisms such as metabolic disturbances, myocardial fibrosis, microvascular dysfunction, cardiac autonomic neuropathy and insulin resistance have been proposed to contribute to structural and functional myocardial impairment 
leading to a pathological condition known as diabetic cardiomyopathy. ${ }^{78}$

Recently, there has been much interest in subclinical stage B heart failure (SBHF) in patients with T2DM. Before the development of symptomatic heart failure, as much as $50 \%$ of patients with T2DM have asymptomatic left ventricular dysfunction (LVD) ${ }^{9}{ }^{10}$ Four stages of heart failure have been proposed as follows: stage A: high risk for development of heart failure with no structural heart disease, stage B: structural or functional cardiac dysfunction with no signs and symptoms of heart failure, stage C: clinical manifestations of heart failure and stage D: end stage or refractory heart failure. ${ }^{10}$ Cardiac imaging plays a crucial role in diagnosis of SBHF. Definition of SBHF includes the presence of at least one of the following echocardiographic parameters: (1) left ventricular hypertrophy, (2) left atrial enlargement (LAE), (3) abnormal $\mathrm{E} / \mathrm{E}^{\prime}$ and impaired global longitudinal strain (GLS). ${ }^{11}$ One year mortality of SBHF was reported as $5 \%-10 \%$ which increases to $15 \%-30 \%$ if the disease progress to stage $\mathrm{C}$ heart failure and to $>50 \%$ in stage $\mathrm{D}$ heart failure. Early identification of preclinical stage of heart failure may propose early initiation of intensive therapies that will delay or prevent the disease progression to overt heart failure.

The aim of our study was to identify the prevalence of preclinical stage of LVD (SBHF) in patients with T2DM with no history of coronary artery disease or heart failure. Previous studies exploring asymptomatic LVD in T2DM have mainly been reported in the Western world and Caucasian populations.

\section{METHODS}

\section{Study design}

This is a single-centre observational (cross-sectional) study in which clinical and echocardiographic characteristics of T2DM patients were examined. A total of 305 patients were recruited. Patients with history of heart failure, coronary artery disease, valvular heart disease, cardiac arrhythmia, congenital heart disease, cardiomyopathy, deranged liver function test and end stage renal failure were excluded. Eligibility of patients was assessed by questionnaire and physical examination. New York Heart Association (NYHA) classification and Canadian Cardiovascular Society (CCS) grading of angina pectoris (CCS Angina Grading Scale or CCS Functional Classification of Angina) were used to access functional and angina status. Laboratory investigations and 2-dimensional echocardiography were performed on patients after informed consent.

Echocardiographic parameters such as left ventricular ejection function (LVEF), left ventricular mass index (LVMI), left atrial volume index (LAVI), left ventricular wall thickness, E/A ratio of trans mitral flow, deceleration time (DT) and diastolic function were recorded. LVEF was determined by using biplane modified Simpson's measurements. The mitral flow was assessed in the apical four-chamber view by pulsed wave Doppler. Diastolic dysfunction was identified according to updated 2016 American Society of Echocardiography guideline. Left ventricular mass was calculated by using Devereux and Reichek 'cube' formula: LV mass $(\mathrm{g})=0.8\{1.04$ [ ( [LVEDD $\left.\left.\left.+\mathrm{IVSd}+\mathrm{PWd}]^{3}-\mathrm{LVEDD}^{3}\right)\right]\right\}+0.6$. LVMI was indexed according to individual body surface area and categorised into normal and increased LVMI by taking account of gender as follows; normal range in female $43-95 \mathrm{~g}$ / $\mathrm{m}^{2}$, male $49-115 \mathrm{~g} / \mathrm{m}^{2}$. Calculation of relative wall thickness (RWT) with the formula (2x posterior wall thickness)/(LV internal diameter at end diastole) permitted further categorisation of increase LVMI as either concentric (RWT $>0.42$ ) or eccentric (RWT $<0.42$ ) hypertrophy. Patients whose LVMI within normal range were identified as having concentric remodelling and normal geometry accordingly, based on RWT results. LAVI was measured from standard apical two chamber and four chamber views. Volume was calculated by using arealength approximation: 8/3ळ (A1xA2/L) and indexed to body surface area (BSA). LAE was defined as LAVi $\geq 34 \mathrm{~mL} / \mathrm{m}^{2}{ }^{12}$

Blood tests were taken for $\mathrm{HbAlc}$ and B-type natriuretic peptide (BNP). The evaluation of BNP levels was done by analysing plasma using Siemens Advia Centaur assay which is an automated two site sandwich chemiluminescent immunoassay.

\section{Patient and public involvement}

Patients and/or the public were not involved in the design, or conduct, or reporting or dissemination plans of this research.

\section{Data variables}

Demographic characteristics, coexisting medical conditions, current medications, established macrovascular (peripheral and cerebrovascular diseases) and microvascular (retinopathy, neuropathy and nephropathy) complications, echocardiographic parameters and laboratory investigations results were recorded.

\section{Statistical analysis}

Descriptive statistics were used for analysis of demographic characteristics. Continuous variables were expressed as mean \pm SD. The differences between normally distributed numeric variables were evaluated by t-test or one-way analysis of variance, while non-normally distributed variables were analysed by Mann-Whitney U test or Kruskal-Wallis variance analysis, as appropriate. $\mathrm{X}^{2}$ test was employed for the comparison of categorical variables and testing the null hypothesis. Multivariable logistic regression analysis was done to identify the association of independent variables to LVD. Correlations of LVMI with baseline characteristics and echocardiographic parameters were checked by multivariable linear regression analysis. All data were analysed by SPSS. 
Table 1 Demographic characteristics, concomitant risk factors, current medication and laboratory investigations of T2DM patients with asymptomatic stage $B$ heart failure and normal left ventricular function

\begin{tabular}{|c|c|c|c|c|}
\hline Variables & $\begin{array}{l}\text { Total study population } \\
\text { (305 patients) }\end{array}$ & $\begin{array}{l}\text { Stage B heart failure } \\
\text { (174 patients, } 57 \% \text { ) }\end{array}$ & $\begin{array}{l}\text { Normal LV function } \\
\text { (131 patients, 43\%) }\end{array}$ & $P$ value \\
\hline Age (years) & $62 \pm 10$ & $64 \pm 10$ & $60 \pm 10$ & 0.001 \\
\hline Age more than 60 years & $200(65.6 \%)$ & $123(70.7 \%)$ & 77 (58.8\%) & 0.030 \\
\hline Male & $108(35.4 \%)$ & $46(26.4 \%)$ & $62(47.3 \%)$ & 0.000 \\
\hline Female & $197(64.6 \%)$ & $128(73.6 \%)$ & $69(52.7 \%)$ & 0.000 \\
\hline $\operatorname{BMI}\left(\mathrm{kg} / \mathrm{m}^{2}\right)$ & $27.5 \pm 4.9$ & $27.7 \pm 4.7$ & $27.2 \pm 5.1$ & 0.383 \\
\hline Malay & $88(28.9 \%)$ & $54(31.0 \%)$ & $34(26.0 \%)$ & \\
\hline Chinese & $87(28.5 \%)$ & 59 (33.9\%) & $28(21.4 \%)$ & \\
\hline India & $124(40.7 \%)$ & $57(32.8 \%)$ & $67(51.1 \%)$ & \\
\hline Active smokers & $25(8.3 \%)$ & 14 (8.09\%) & $11(8.4 \%)$ & 0.879 \\
\hline Alcohol & $31(10.3 \%)$ & $12(7.0 \%)$ & $19(14.7 \%)$ & 0.088 \\
\hline More than 10 years & $254(83.3 \%)$ & $149(85.6 \%)$ & $105(80.2 \%)$ & \\
\hline Hypertension & $234(76.7 \%)$ & $144(82.8 \%)$ & $90(68.7 \%)$ & 0.004 \\
\hline Systolic blood pressure $(\mathrm{mm} \mathrm{Hg})$ & $137 \pm 17$ & $139 \pm 17$ & $134 \pm 16$ & 0.006 \\
\hline Diastolic blood pressure (mm Hg) & $74 \pm 11$ & $74 \pm 11$ & $74 \pm 11$ & 0.706 \\
\hline Heart rate (beats/min) & $85 \pm 14$ & $84 \pm 13$ & $85 \pm 16$ & 0.581 \\
\hline Dyslipidaemia & $278(91.1 \%)$ & $161(92.5 \%)$ & $117(89.3 \%)$ & 0.328 \\
\hline \multicolumn{5}{|l|}{ T2DM-related complications } \\
\hline Cerebrovascular accidents & $16(5.2 \%)$ & $11(6.3 \%)$ & $5(3.8 \%)$ & 0.331 \\
\hline Peripheral vascular disease & $6(2.0 \%)$ & $4(2.3 \%)$ & $2(1.5 \%)$ & 0.631 \\
\hline $\mathrm{BNP}(\mathrm{pg} / \mathrm{mL})$ & $18(7,33)$ & $24(11,41)$ & $11(5,22)$ & \\
\hline \multicolumn{5}{|l|}{ Current medications } \\
\hline Metformin & $279(91.5 \%)$ & $158(90.8 \%)$ & $121(92.4 \%)$ & 0.629 \\
\hline Sulphonylurea & $93(30.5 \%)$ & $54(31.0 \%)$ & $39(29.8 \%)$ & 0.812 \\
\hline DPP4i & $122(40.0 \%)$ & $71(40.8 \%)$ & $51(38.9 \%)$ & 0.741 \\
\hline SGLT2i & $127(41.6 \%)$ & $66(37.9 \%)$ & $61(46.6 \%)$ & 0.130 \\
\hline GLP-1RA & $26(8.5 \%)$ & $11(6.3 \%)$ & $15(11.5 \%)$ & 0.112 \\
\hline Insulin & $186(61.0 \%)$ & $106(60.9 \%)$ & $80(61.1 \%)$ & 0.979 \\
\hline ACEI & 227 (74.4\%) & $130(74.7 \%)$ & $97(74.0 \%)$ & 0.895 \\
\hline ССВ & $139(45.6 \%)$ & 93 (53.4\%) & $46(35.1 \%)$ & 0.001 \\
\hline Diuretics & 55 (18.0\%) & 37 (21.3\%) & $18(13.7 \%)$ & 0.091 \\
\hline Beta blockers & $42(13.8 \%)$ & $28(16.1 \%)$ & $14(10.7 \%)$ & 0.175 \\
\hline Statin & 275 (90.2\%) & 156 (89.7\%) & 119 (90.8\%) & 0.731 \\
\hline Aspirin & $205(67.2 \%)$ & $116(66.7 \%)$ & 89 (67.9\%) & 0.815 \\
\hline Clopidogrel & $9(3.0 \%)$ & $4(2.3 \%)$ & $5(3.8 \%)$ & 0.438 \\
\hline
\end{tabular}

ACEI, angiotensin converting enzyme inhibitors; BMI, body mass index; BNP, B-type natriuretic peptide; CCB, calcium channel blockers; DPP4i, dipeptidyl peptidase 4 (DPP-4) inhibitors; eGFR, glomerular filtration rate; GLP-1RA, glucagon-like peptide-1 receptor agonist; LV, left ventricular; SGLT2i, sodium-glucose transport protein 2 inhibitors; T2DM, type 2 diabetes mellitus. 
Table 2 Echocardiographic parameters of study populations divided according to left ventricular function

\begin{tabular}{|c|c|c|c|c|}
\hline Variables & $\begin{array}{l}\text { Total study } \\
\text { population } \\
\text { (305 patients) }\end{array}$ & $\begin{array}{l}\text { Stage B heart } \\
\text { failure } \\
\text { (174 patients, } 57 \% \text { ) }\end{array}$ & $\begin{array}{l}\text { Normal LV function } \\
\text { (131 patients, } 43 \%)\end{array}$ & $P$ value \\
\hline Left ventricular ejection fraction (\%) & $68 \pm 4$ & $68 \pm 4$ & $67 \pm 4$ & 0.062 \\
\hline E wave of transmitral flow $(\mathrm{cm} / \mathrm{s})$ & $63.98 \pm 17.45$ & $63.83 \pm 18.21$ & $64.18 \pm 16.46$ & 0.863 \\
\hline E/A ratio & $108(35.4 \%)$ & $0.77 \pm 0.25$ & $0.82 \pm 0.26$ & 0.089 \\
\hline Deceleration time (msec) & 197 (64.6\%) & $218.87 \pm 63.43$ & $216.34 \pm 52.52$ & 0.713 \\
\hline E/E' ratio & $9.63 \pm 2.98$ & $16.33 \pm 3.44$ & $8.98 \pm 2.07$ & 0.001 \\
\hline Diastolic function & & & & 0.0003 \\
\hline Normal & 254 (83.3\%) & $123(70.7 \%)$ & 131 (100.0\%) & \\
\hline Indeterminate & $43(14.1 \%)$ & $43(24.7 \%)$ & $0(0.00 \%)$ & \\
\hline Diastolic dysfunction & $8(2.6 \%)$ & $8(4.6 \%)$ & $0(0.00 \%)$ & \\
\hline LV EDD (cm) & $4.45 \pm 0.60$ & $4.5 \pm 0.6$ & $4.3 \pm 0.5$ & 0.0002 \\
\hline Relative wall thickness $(\mathrm{cm})$ & $0.41 \pm 0.12$ & $0.44 \pm 0.13$ & $0.40 \pm 0.12$ & 0.072 \\
\hline Left atrial volume $(\mathrm{mL})$ & $39.14 \pm 12.58$ & $44.39 \pm 12.90$ & $32.17 \pm 7.91$ & 0.0001 \\
\hline Left atrial volume index $\left(\mathrm{mL} / \mathrm{m}^{2}\right)$ & $22.77 \pm 7.10$ & $34.86 \pm 7.11$ & $18.36 \pm 4.02$ & 0.0002 \\
\hline Reference range & $207(67.9 \%)$ & $76(43.7 \%)$ & $131(100.0 \%)$ & \\
\hline Mild abnormal & $56(18.4 \%)$ & $56(32.2 \%)$ & $0(0.00 \%)$ & \\
\hline Moderate abnormal & $40(13.1 \%)$ & $40(23.0 \%)$ & $0(0.00 \%)$ & \\
\hline Severe abnormal & $2(0.7 \%)$ & $2(1.1 \%)$ & $0(0.00 \%)$ & \\
\hline Left ventricular mass (g) & $176.57 \pm 63.70$ & $201.67 \pm 68.61$ & $143.42 \pm 68.61$ & 0.0002 \\
\hline Left ventricular mass index $\left(\mathrm{g} / \mathrm{m}^{2}\right)$ & $101.08 \pm 32.29$ & $115.98 \pm 33.40$ & $81.40 \pm 16.37$ & 0.0001 \\
\hline Reference range & $177(58.0 \%)$ & $46(26.4 \%)$ & $131(100.0 \%)$ & \\
\hline Mild abnormal & $45(14.8 \%)$ & $45(25.9 \%)$ & & \\
\hline Moderate abnormal & $33(10.8 \%)$ & $33(19.0 \%)$ & & \\
\hline Severe abnormal & $50(16.4 \%)$ & $50(28.7 \%)$ & & \\
\hline \multicolumn{5}{|l|}{ Left ventricular hypertrophy } \\
\hline Eccentric hypertrophy & & $52(17.0 \%)$ & & \\
\hline Concentric hypertrophy & & $76(24.9 \%)$ & & \\
\hline Concentric remodelling & & & $71(23.3 \%)$ & \\
\hline Normal geometry & & & 106 (34.8\%) & \\
\hline
\end{tabular}

LV EDD, left ventricular end diastolic diameter.

\section{DATA AVAILABILITY}

The data sets used and/or analysed are available from the corresponding author on reasonable request.

\section{RESULTS}

A total of 305 patients (mean age of $62.78 \pm 10.58$ years) participated in this study. Female predominance $(65 \%)$ with mean BMI of $27.47 \pm 4.88 \mathrm{~kg} / \mathrm{m}^{2}$ were noted. Patients of Indian ethnicity constituted $41 \%$ of study population. Twenty-five patients $(3.3 \%)$ were noted as active smoker and 31 patients $(10.2 \%)$ were recorded as current alcohol consumers. Coexisting hypertension was present in 234 patients $(77 \%)$ and dyslipidaemia in 278 patients (91\%). Majority of study population (253 patients, $83 \%$ ) were known to have diabetes for more than 10 years. Mean HbAlc of $8.3 \% \pm 1.8 \%$ was recorded. Only 67 patients
(22\%) had $\mathrm{HbAlc}<7 \%$ at the time of study. Almost all patients $(92 \%)$ were on metformin and $61 \%$ were on insulin. Only $40 \%$ of study population were taking newer antidiabetic medications such as sodium-glucose cotransporter $2 \mathrm{i}$ and dipeptidyl peptidase $4 \mathrm{i}$.

More than one-third of patients (114 patients, 37\%) were diagnosed to have microvascular complications such as retinopathy in 67 patients (22\%), neuropathy in 56 patients $(18 \%)$ and albuminuria in 86 patients $(28 \%)$. Macrovascular complications were noted in 21 patients $(7 \%)$ as follows; peripheral vascular disease (PVD) in six patients $(2 \%)$ and cerebrovascular accident (CVA) in 16 patients (5\%). 99\% of patients (302 patients) fell into NYHA class I. Two hundred and nighty-eight patients $(98 \%)$ were totally free from angina symptoms and classified as CCS class 0. Clinical examinations revealed none of 
Table 3 Logistic regression analysis for predictors of stage $B$ heart failure in T2DM patients

\begin{tabular}{|c|c|c|c|}
\hline Variable & HR & $95 \% \mathrm{Cl}$ & $P$ value \\
\hline Age & 1.027 & 0.978 to 1.078 & 0.282 \\
\hline Age $>60$ & 1.197 & 0.453 to 3.166 & 0.717 \\
\hline Female gender* & 3.305 & 1.811 to 6.031 & 0.000 \\
\hline Ethnic Chinese† & 1.922 & 0.867 to 4.261 & 0.108 \\
\hline Ethnic Indian† & 0.445 & 0.229 to 0.864 & 0.017 \\
\hline BMI & 1.137 & 1.059 to 1.221 & 0.000 \\
\hline \multicolumn{4}{|l|}{ Duration of diabetes } \\
\hline 5-10years $\ddagger$ & 1.356 & 0.264 to 6.952 & 0.715 \\
\hline More than 10 years $\ddagger$ & 1.317 & 0.320 to 5.418 & 0.703 \\
\hline Hypertension & 1.758 & 0.767 to 2.367 & 0.890 \\
\hline \multicolumn{4}{|l|}{ Duration of hypertension } \\
\hline 5-10years§ & 3.791 & 0.400 to 35.898 & 0.245 \\
\hline More than 10 years§ & 5.040 & 0.591 to 42.992 & 0.139 \\
\hline Dyslipidaemia & 6.233 & 1.478 to 26.295 & 0.013 \\
\hline PVD & 1.208 & 0.135 to 10.763 & 0.866 \\
\hline CVA & 1.364 & 0.350 to 5.314 & 0.654 \\
\hline Albuminuria & 1.474 & 0.684 to 3.177 & 0.322 \\
\hline Neuropathy & 1.004 & 0.397 to 2.539 & 0.993 \\
\hline Retinopathy & 0.744 & 0.323 to 1.714 & 0.487 \\
\hline $\mathrm{HbA1c}$ & 0.966 & 0.812 to 1.148 & 0.692 \\
\hline BNP & 4.227 & 2.441 to 7.318 & 0.0003 \\
\hline eGFR & 0.976 & 0.961 to 0.991 & 0.001 \\
\hline Metformin & 1.039 & 0.369 to 2.922 & 0.943 \\
\hline Sulfonylurea & 1.315 & 0.657 to 2.629 & 0.439 \\
\hline DPP4i & 1.347 & 0.740 to 2.451 & 0.330 \\
\hline SGLT2i & 0.632 & 0.346 to 1.154 & 0.135 \\
\hline GLP1-RA & 0.397 & 0.137 to 1.148 & 0.088 \\
\hline Insulin & 1.076 & 0.520 to 2.225 & 0.843 \\
\hline ACE/ARB & 0.268 & 0.104 to 0.689 & 0.006 \\
\hline СCB & 1.468 & 0.766 to 2.813 & 0.247 \\
\hline Beta blocker & 0.575 & 0.235 to 1.405 & 0.224 \\
\hline Statin & 0.227 & 0.054 to 0.947 & 0.042 \\
\hline AV calcifications & 1.262 & 0.296 to 5.380 & 0.753 \\
\hline RWT & 5.282 & 0.693 to 40.245 & 0.108 \\
\hline Left atrial volume & 0.854 & 0.696 to 1.049 & 0.134 \\
\hline Left atrial volume index & 1.732 & 1.201 to 2.500 & 0.003 \\
\hline Left ventricular mass & 1.011 & 0.969 to 1.055 & 0.613 \\
\hline $\begin{array}{l}\text { Left ventricular mass } \\
\text { index }\end{array}$ & 1.066 & 0.986 to 1.151 & 0.109 \\
\hline
\end{tabular}

*Male gender is the reference.

†Malay ethnic is the reference.

fDM for less than 5 years is the reference.

$\S$ Hypertension for less than 5 years is the reference.

$\mathrm{ACE}$, angiotensin-converting enzyme ; ARB, angiotensin II

receptor blockers; AV, Aortic Valve; BMI, body mass index; BNP,

B-type natriuretic peptide; CCB, calcium channel blockers; CVA, cerebrovascular accident; DPP4i, dipeptidyl peptidase 4 inhibitors; eGFR, glomerular filtration rate; GLP1-RA, glucagon-like peptide-1 receptor agonist; PVD, peripheral vascular disease; RWT, relative wall thickness; SGLT2i, sodium-glucose transport protein 2 inhibitors; T2DM, type 2 diabetes mellitus. the recruited patients had signs of heart failure. Normal BNP result was recorded in $98 \%$ our study population.

Normal left ventricular systolic function with mean LVEF of $68 \% \pm 4 \%$ was identified. One hundred and seventy-four patients (57\%) had SBHF. Diastolic dysfunction, increased LVMI and increased LAVI were noted in 51 patients (17\%), 128 patients $(42 \%)$ and 98 patients $(32 \%)$, respectively. Thirty-seven patients $(12 \%)$ were having both increase LVMI and LAVI. Concentric hypertrophy (RWT $>0.42$ ) was identified in 76 patients $(25 \%)$ and eccentric hypertrophy (RWT $\leq 0.42$ ) was noted in 52 patients $(17 \%)$ of patients with increased LVMI. Concentric remodelling in 71 patients (23\%) and the rest 105 patients (34\%) were diagnosed with normal geometry.

Demographic characteristics, concomitant risk factors, current medications and laboratory results among patients with asymptomatic LV dysfunction and normal LV function were shown in table 1. Older age group, female predominance, higher mean BMI, lower mean glomerular filtration rate (eGFR) and higher BNP were noted in SBHF patient group. Pre-existing comorbid conditions such as hypertension and dyslipidaemia were more commonly seen in these patients. Microvascular and macrovascular manifestations were also more prevalent in patients with SBHF. Statistically significant differences in echocardiographic parameters among two groups of patients were identified. Higher mean $\mathrm{E} / \mathrm{E}^{\prime}$ ratio, left ventricular end diastolic diameter, LAVI and LVMI were noted in patients with SBHF (table 2).

Multivariate logistic regression analysis identified that female gender (HR: 3.305 (95\% CI: 1.811 to 6.031), $\mathrm{p}=0.000098$ ), higher BMI (HR: 1.137 (95\% CI: 1.059 to 1.221), $\mathrm{p}=0.000425)$, hypercholesterolemia (HR: 6.233 (95\% CI: 1.478 to 26.295$), \mathrm{p}=0.013$ ) and LAVI (HR: 1.732 (95\% CI: 1.201 to 2.500 ), $\mathrm{p}=0.003$ ) were statistically significant predictors of SBHF. Higher eGFR, usage of $\mathrm{ACE} / \mathrm{ARB}$ and statin were found out to have protective effect on the development of SBHF. Older age, coexisting hypertension, longer duration of diabetes, hypertension and the presence of microvascular and macrovascular manifestations were predictors of asymptomatic LV dysfunction but none of them reach statistically significant $p$ value (table 3 ).

Subgroup analysis on echocardiographic parameters on the presence of hypertension was evaluated in T2DM patients with $(\mathrm{n}=234,77 \%)$ and without hypertension $(\mathrm{n}=71,23 \%)$. Normal left ventricular systolic function with similar mean LVEF was noted in both patient groups. Statistically significant higher average E/E', left atrial volume and LAVI were noted in T2DM patients with hypertension. SBHF was noted more commonly in patients with hypertension (61.5\% vs $42.3 \%$ ) (table 4 ).

\section{DISCUSSION}

Our study cohort represents real-world asymptomatic T2DM patient group. It showed similar demographic characteristics (mean age of $63 \pm 11$ years, female predominance) 
Table 4 Echocardiographic parameters among diabetic patients with or without hypertension

\begin{tabular}{|c|c|c|c|}
\hline Parameter & T2DM with HTN ( $n=234)$ & T2DM without HTN ( $n=71)$ & $P$ value \\
\hline Ejection fraction (\%) & $68.28 \pm 4.53$ & $68.24 \pm 4.32$ & 0.950 \\
\hline Left ventricular mass (g) & $176.96 \pm 65.29$ & $175.29 \pm 58.60$ & 0.847 \\
\hline LVMI $\left(g / m^{2}\right)$ & $101.27 \pm 33.16$ & $100.44 \pm 29.48$ & 0.850 \\
\hline Reference range & $132(56.4 \%)$ & $45(63.4 \%)$ & 0.404 \\
\hline Mild abnormal & $34(14.5 \%)$ & $11(15.5 \%)$ & \\
\hline Moderate abnormal & $25(10.7 \%)$ & $8(11.3 \%)$ & \\
\hline Severe abnormal & $43(18.4 \%)$ & $7(9.9 \%)$ & \\
\hline E velocity $(\mathrm{m} / \mathrm{sec})$ & $64.34 \pm 17.19$ & $63.95 \pm 17.55$ & 0.960 \\
\hline$E / A$ & $0.76 \pm 0.23$ & $0.91 \pm 0.32$ & 0.0004 \\
\hline DT (msec) & $219.67 \pm 60.52$ & $211.31 \pm 52.68$ & 0.304 \\
\hline Average $\mathrm{E} / \mathrm{E}^{\prime}$ & $9.94 \pm 3.12$ & $8.64 \pm 2.21$ & 0.001 \\
\hline Relative wall thickness & $0.43 \pm 0.13$ & $0.42 \pm 0.098$ & 0.630 \\
\hline Left ventricular end diastolic diameter $(\mathrm{cm})$ & $4.44 \pm 0.62481$ & $4.48 \pm 0.49$ & 0.578 \\
\hline Diastolic function & & & 0.103 \\
\hline Normal & $189(80.8 \%)$ & $65(91.5 \%)$ & \\
\hline Indeterminate & $38(16.2 \%)$ & $5(7.0 \%)$ & \\
\hline Abnormal & $7(3.0 \%)$ & $1(1.4 \%)$ & \\
\hline Left atrial volume & $40.32 \pm 12.65$ & $35.27 \pm 11.60$ & 0.003 \\
\hline Left atrial volume index $\left(\mathrm{mL} / \mathrm{m}^{2}\right)$ & $23.47 \pm 7.18$ & $20.46 \pm 6.31$ & 0.001 \\
\hline Reference range & $150(64.1 \%)$ & $57(80.3 \%)$ & 0.079 \\
\hline Mild abnormal & $48(20.5 \%)$ & $8(11.3 \%)$ & \\
\hline Moderate abnormal & $34(14.5 \%)$ & $6(8.5 \%)$ & \\
\hline Severe abnormal & $2(0.9 \%)$ & 0 & \\
\hline Stage B heart failure & $144(61.5 \%)$ & $30(42.3 \%)$ & 0.004 \\
\hline
\end{tabular}

DT, deceleration time; HTN, hypertension; LVMI, left ventricular mass index; T2DM, type 2 diabetes mellitus.

and prevalence of comorbidities (HTN in 77\% and dyslipidaemia $91 \%$ of study population) as previous reports. ${ }^{13-15}$ Mean BMI of $27.47 \pm 4.88 \mathrm{~kg} / \mathrm{m}^{2}$ with higher percentage of patients $(85 \%)$ were identified as overweight/obese in our study compared with previous study conducted in Malaysia that had reported similar prevalence $(72 \%-75 \%)$ of patients who are overweight/obese. ${ }^{16}$ In our study cohort, lower prevalence of macrovascular complications such as CVA and PVD $(6.8 \%$ vs $32.2 \%),{ }^{18}$ microvascular complications such as nephropathy (albuminuria only, normal eGFR) $(28.2 \%$ vs $30 \%-50 \%),{ }^{19}$ retinopathy $(22.0 \% \text { vs } 30 \%)^{20}$ and neuropathy $(18.4 \% \text { vs } 30 \%-50 \%)^{21}$ were noted comparing to previous reports. Seventy-eight percent of patients were noted to have poor glycaemic control (study population targeted HbAlc of $6.6 \%-7.0 \%)^{22}$ out of which 56 patients $(18 \%)$ were having $\mathrm{HbAlc}$ of $>10 \%$. Consistent findings on poor glycaemic control in Malaysian T2DM population were noted across various studies over few decades. ${ }^{16} 2324$

Left ventricular diastolic dysfunction with normal systolic function in diabetic patients has been an area of interest over decades. Prevalence of diastolic dysfunction in T2DM patients with preexisting comorbidities ranged from $48 \%$ to $81 \%$ among various studies. ${ }^{25-27}$ Lower prevalence of diastolic dysfunction $(16.7 \%)$ was noted in our study population. Female gender, ageing, high BMI, HbAlc level, diabetic microangiopathies and duration of diabetes have been reported as predictors of incidence of LV diastolic dysfunction. ${ }^{27-29}$ Among them, hypertension has been a debatable coexisting medical condition for the development of LV diastolic dysfunction. ${ }^{25}{ }^{28}$ In terms of treatment strategies, the The American College of Cardiology Foundation/American Heart Association (ACCF/AHA) updated clinical practice guidelines recommend the use of disease modifying medications in an attempt to prevent or delay progression to overt heart failure in patients with high risk factors (stage A heart failure) and asymptomatic structural heart disease (SBHF) to initiate. ${ }^{30}$

There have been previous studies that had reported on the prevalence of SBHF in T2DM patients. In a study conducted in Australia, Wang et al reported a similar prevalence- $58 \%$ of non-ischaemic SBHF in asymptomatic T2DM patients aged $\geq 65$ years with preserved LVEF. Similar echocardiographic parameters were used as our study apart from GLS that was abnormal in $23 \%$ of that study population. ${ }^{31}$ In an earlier study conducted in Italy, the SHORTWAVE investigators reported that $68 \%$ of asymptomatic T2DM patients 
had abnormal circumferential and longitudinal LV systolic functions as well as diastolic dysfunction. ${ }^{9}$ In another Australian study involving patients with at least one cardiovascular risk factors that included T2DM, Yang et al reported that $62 \%$ of Caucasian patients had SBHF. ${ }^{11}$ To put into context, the prevalence of SBHF in the community is approximately $35 \%$ in the Olmsted County community study. ${ }^{32}$ Taking all this into consideration, the prevalence of stage B cardiomyopathy in our study cohort in Malaysia, the prevalence of stage B cardiomyopathy of 57\% is similar to that reported in the Western developed world. This might suggest that the pathophysiology of stage B cardiomyopathy in Malaysia may be similar to that reported in these other populations. In our study, we were not designed to explore the underlying pathophysiology of SBHF. However, there may be a role of coexisting hypertension as a subanalysis of our study showed statistically significant higher prevalence of SBHF in T2DM patients with hypertension compared with those with no history of hypertension ( $61.5 \%$ vs $42.3 \%$, p value $=0.004$ ). Clearly, more studies are needed to better understand the pathophysiology of stage B cardiomyopathy in T2DM.

\section{LIMITATIONS}

There are several limitations in our study. First of all, the concomitant presence of coronary artery disease was not investigated with coronary angiography or coronary CT. We did however rule out coronary artery disease patients as assessed by questionnaire and CCS scoring system. Second, GLS data were not available in our study which is one of the criteria to diagnose SBHF. Lack of data on strain could possibly lead us to underestimate the overall prevalence of SBHF. Third, in terms of an evaluation of T2DM glycaemic control, only a single reading of HbA1c level was available for this assessment. It would have been useful to have determined a mean HbA1c over a period in our analysis. Finally, we do not have follow-up data although plans are underway for follow-up of development of heart failure with repeated echocardiography.

\section{CONCLUSION}

Our study had shown a high prevalence $(57 \%)$ of SBHF in asymptomatic T2DM patients without overt cardiac disease in Malaysia. This high prevalence has similarly been reported in study populations in Western developed countries.

\section{Author affiliations}

${ }^{1}$ Division of Cardiology, Department of Medicine, University Malaya Medical Centre, Kuala Lumpur, Selangor, Malaysia

${ }^{2}$ Department of Medicine, Hospital Queen Elizabeth, Kota Kinabalu, Sabah, Malaysia ${ }^{3}$ Department of Medicine, University Malaya Medical Centre, Kuala Lumpur, Wilayah Persekutuan, Malaysia

${ }^{4}$ Division of Endocrinology, Department of Medicine, University Malaya Medical Centre, Kuala Lumpur, Malaysia

Contributors MMO and KHC: design and idea of the research work; writing the protocol and ethics submission; preparing patient information sheet and consent form; arranging with biochemistry laboratory for the blood investigations and cardiac laboratory for echocardiography; recruiting the patients, physical examination and investigations; data entry, processing, cleaning up the data and analysing the data; writing up the paper and submitting to the journal; editing the paper. KLT: design and idea of the research work; data entry, processing, cleaning up the data and analysing the data; writing up the paper and submitting to the journal. ATBT, SRV and RJA/LR: design and idea of the research work; planning and recruiting the patients from T2DM clinic; data entry, processing and cleaning up the data; interpreting the analysed data and idea to write up the paper; editing the paper.

Funding The authors have not declared a specific grant for this research from any funding agency in the public, commercial or not-for-profit sectors.

Competing interests None declared.

Patient consent for publication Not required.

Ethics approval The study has received ethical approval from the Medical Research and Ethics Committee under University of Malaya Medical Center (MREC ID N0: 20171212-5867).

Provenance and peer review Not commissioned; externally peer reviewed.

Data availability statement Data are available upon reasonable request. The data set used and/or analysed are available from the corresponding author upon reasonable request.

Open access This is an open access article distributed in accordance with the Creative Commons Attribution Non Commercial (CC BY-NC 4.0) license, which permits others to distribute, remix, adapt, build upon this work non-commercially, and license their derivative works on different terms, provided the original work is properly cited, appropriate credit is given, any changes made indicated, and the use is non-commercial. See: http://creativecommons.org/licenses/by-nc/4.0/.

\section{ORCID iD}

Mon Myat 0o http://orcid.org/0000-0003-3534-7605

\section{REFERENCES}

1 World Health Organization. Global report on diabetes. Geneva, Switzerland, 2016.

2 Alessandra DC, Sadiya SK, Javed B. Impact of diabetes on epidemiology, treatment, and outcomes of patients with heart failure. ISSN 1779;221:3.

3 Metra M, Zac V, Parati G. Cardiovascular and noncardiovascular comorbidities in patients with chronic heart failure. Heart Failure Study Group of the Italian Society of Cardiology. J Cardiovasc Med 2011;12:76-84.

4 Butler J, Fonarow GC, Gheorghiade M. Need for increased awareness and evidence-based therapies for patients hospitalized for heart failure. JAMA 2013;310:2035-6.

5 Kannel WB, McGee DL. Diabetes and cardiovascular disease. The Framingham study. JAMA 1979;241:2035-8.

6 Barrett-Connor E, Giardina E-GV, Gitt AK, et al. Women and heart disease. Arch Intern Med 2004;164:934.

7 Cherian S, Lopaschuk GD, Carvalho E. Cellular cross-talk between epicardial adipose tissue and myocardium in relation to the pathogenesis of cardiovascular disease. Am J Physiol Endocrinol Metab 2012;303:E937-49.

8 Fang ZY, Prins JB, Marwick TH. Diabetic cardiomyopathy: evidence, mechanisms, and therapeutic implications. Endocr Rev 2004:25:543-67.

9 Faden G, Faganello G, De Feo S, et al. The increasing detection of asymptomatic left ventricular dysfunction in patients with type 2 diabetes mellitus without overt cardiac disease: data from the SHORTWAVE study. Diabetes Res Clin Pract 2013;101:309-16.

10 Lam CS. Diabetic cardiomyopathy: an expression of stage B heart failure with preserved ejection fraction. Diab Vasc Dis Res 2015;12:234-8

11 Yang $\mathrm{H}$, Negishi K, Wang $\mathrm{Y}$, et al. Echocardiographic screening for non-ischaemic stage $B$ heart failure in the community. Eur $J$ Heart Fail 2016;18:1331-9.

12 Lang RM, Badano LP, Mor-Avi V, et al. Recommendations for cardiac chamber quantification by echocardiography in adults: an update from the American Society of echocardiography and the European association of cardiovascular imaging. J Am Soc Echocardiogr 2015;28:1-39.

13 Tee E-S, Yap RWK. Type 2 diabetes mellitus in Malaysia: current trends and risk factors. Eur J Clin Nutr 2017;71:844-9.

14 Narindrarangkura P, Bosl W, Rangsin R, et al. Prevalence of dyslipidemia associated with complications in diabetic patients: a nationwide study in Thailand. Lipids Health Dis 2019;18:90. 
15 Li Y, Zhao L, Yu D, et al. The prevalence and risk factors of dyslipidemia in different diabetic progression stages among middleaged and elderly populations in China. PLoS One 2018;13:e0205709.

16 Mafauzy M, Hussein Z, Chan SP. The status of diabetes control in Malaysia: results of DiabCare 2008. Med J Malaysia 2011;66:175-81.

17 Daousi C, Casson IF, Gill GV, et al. Prevalence of obesity in type 2 diabetes in secondary care: association with cardiovascular risk factors. Postgrad Med J 2006;82:280-4.

18 Einarson TR, Acs A, Ludwig C, et al. Prevalence of cardiovascular disease in type 2 diabetes: a systematic literature review of scientific evidence from across the world in 2007-2017. Cardiovasc Diabetol 2018;17:83.

19 Gheith O, Farouk N, Nampoory N, et al. Diabetic kidney disease: world wide difference of prevalence and risk factors. $J$ Nephropharmacol 2016;5:49-56.

20 Ruta LM, Magliano DJ, Lemesurier R, et al. Prevalence of diabetic retinopathy in type 2 diabetes in developing and developed countries. Diabet Med 2013;30:387-98.

21 Juster-Switlyk K, Smith AG. Updates in diabetic peripheral neuropathy. F1000Res 2016;5:738.

22 Malaysia revised and updated clinical practice guidelines (CpG) on management of type 2 diabetes mellitus, 2015. Available: http:// www.moh.gov.my

23 Mohamed M, Diabcare-Asia 2003 Study Group. An audit on diabetes management in Asian patients treated by specialists: the DiabcareAsia 1998 and 2003 studies. Curr Med Res Opin 2008;24:507-14.

24 Hafizuddin A, Siti Mariam J, Nurul A. Poor glycemic control: prevalence and risk factors among patients with type 2 diabetes mellitus in northeast state of Peninsular Malaysia. Inter J Human Health Sci;04:206-14.
25 Liu JE, Palmieri V, Roman MJ, et al. The impact of diabetes on left ventricular filling pattern in normotensive and hypertensive adults: the strong heart study. J Am Coll Cardiol 2001;37:1943-9.

26 Kiencke S, Handschin R, von Dahlen R, et al. Pre-clinical diabetic cardiomyopathy: prevalence, screening, and outcome. Eur $\mathrm{J}$ Heart Fail 2010;12:951-7.

27 Patil VC, Patil HV, Shah KB, et al. Diastolic dysfunction in asymptomatic type 2 diabetes mellitus with normal systolic function. J Cardiovasc Dis Res 2011;2:213-22.

28 Masugata H, Senda S, Goda F, et al. Left ventricular diastolic dysfunction in normotensive diabetic patients in various age strata. Diabetes Res Clin Pract 2008;79:91-6.

29 From AM, Scott CG, Chen $\mathrm{HH}$. Changes in diastolic dysfunction in diabetes mellitus over time. Am J Cardiol 2009;103:1463-6.

30 Hunt SA, Abraham WT, Chin MH. Focused update incorporated into the ACC/AHA 2005 guidelines for the diagnosis and management of heart failure in adults: a report of the American College of cardiology Foundation/American heart association Task force on practice guidelines. J Am Coll Cardiol 2009;2009:e1-90.

31 Wang $\mathrm{Y}$, Yang $\mathrm{H}$, Huynh $\mathrm{Q}$, et al. Diagnosis of nonischemic stage $\mathrm{B}$ heart failure in type 2 diabetes mellitus: optimal parameters for prediction of heart failure. JACC Cardiovasc Imaging 2018;11:1390-400.

32 Ammar KA, Jacobsen SJ, Mahoney DW, et al. Prevalence and prognostic significance of heart failure stages: application of the American College of Cardiology/American heart association heart failure staging criteria in the community. Circulation 2007;115:1563-70. 